\title{
Análisis comparativo del ciclo gametogénico de Perumytilus purpuratus (Bivalvia: Mytilidae), en las localidades de Taltal y Huasco, norte de Chile
}

\author{
Comparative analysis of the gametogenic cycle from Perumytilus purpuratus \\ (Bivalvia: Mytilidae), at the localities of Taltal and Huasco, northern Chile \\ Pablo Oyarzún Cabañas ${ }^{1}$, Jorge E. Toro ${ }^{1}$, Roberto Jaramillo², \\ Ricardo Guiñez ${ }^{3}$, Carolina Briones ${ }^{4}$ y Marcela Astorga ${ }^{5}$ \\ ${ }^{1}$ Instituto de Biología Marina 'Dr. Jürgen Winter', Universidad Austral de Chile, Valdivia, Chile \\ ${ }^{2}$ Instituto de Embriología, Universidad Austral de Chile, Casilla 567, Valdivia, Chile \\ ${ }^{3}$ Instituto de Investigaciones Oceanológicas, Facultad de Recursos del Mar, \\ Universidad de Antofagasta, Casilla 170, Antofagasta, Chile \\ ${ }^{4}$ Programa Doctorado en Ciencias Aplicadas, mención Sistemas Marinos Costeros, \\ Facultad de Recursos del Mar, Universidad de Antofagasta, Antofagasta, Chile \\ ${ }^{5}$ Instituto de Acuicultura \& CIEN-Austral, Universidad Austral de Chile, \\ Sede Puerto Montt, Casilla 1327, Puerto Montt, Chile \\ jtoro@uach.cl
}

\begin{abstract}
A qualitative and quantitative study of the gametogenic cycle from natural populations of Perumytilus purpuratus at the localities of Taltal and Huasco was carried out between October 2007 and October 2008. By means of histological analysis a gonadal maturation table was constructed according to the microscopic characteristics. Also the Gametic Volume Fraction (GVF) (\% of previtelogenic oocytes, vitelogenic oocytes and mature oocytes), percentaje of interfolicular connective tissue and Gonadic Index (GI) were determined. According to the qualitative analysis, P. purpuratus has a semiannual reproductive cycle starting in January with spawning mainly during spring-summer, even do some winter spawning were detected. However, the quantitative analysis of mature oocytes percentajes found that at Taltal population four spawnings were detected (December, March, July and October) while in Huasco population three spawnings were detected (December, February and September). The relationship between GI with the gametogenic stages and the mature oocyte percentajes were significant at the localities studied. Also significant differences of the condition index between males and females were observed. Along the latitudinal gradient the reproductive cycle of $P$. purpuratus showed variations according to the timing and synchrony.
\end{abstract}

Key words: Spawning, reproductive cycle, maico mussel, gametic volume fraction
Resumen.- Se estudió el ciclo gametogénico de forma cualitativa y cuantitativa en poblaciones naturales de Perumytilus purpuratus provenientes de las localidades de Taltal y Huasco, Chile, durante el período entre octubre de 2007 y octubre de 2008. A través del análisis histológico se construyó una tabla de madurez gonadal de acuerdo a las características microscópicas. También se determinó el volumen de la fracción gamética (VFG) (\% de ovocitos previtelogénicos, ovocitos vitelogénicos y ovocitos maduros), porcentaje de tejido interfolicular e índice gonadal (IG). De acuerdo al análisis cualitativo P. purpuratus tiene un ciclo reproductivo semi-anual, que comienza en enero con desoves principalmente en primavera-verano, aunque también se detectaron desoves invernales. Sin embargo, el análisis cuantitativo de porcentajes de ovocitos maduros encontró que en Taltal se produjeron cuatro desoves (diciembre, marzo, julio y octubre) mientras que en Huasco tres (diciembre, febrero y septiembre). La relación del IG con los estados gametogénicos y el porcentaje de ovocitos maduros es significativa en las localidades estudiadas. También se observaron diferencias significativas del índice gonadal entre machos y hembras. En un gradiente latitudinal, el ciclo reproductivo de $P$. purpuratus mostró variaciones de acuerdo al periodo y a la sincronía.

Palabras clave: Desove, ciclo reproductivo, chorito maico, volumen de la fracción gamética 


\section{Introducción}

En general, los ciclo reproductivos de los invertebrados marinos son afectados por factores ambientales tales como la latitud, temperatura del agua, salinidad, fotoperíodo y la disponibilidad de alimento, entre otros (Seed 1976, Giese \& Pearse 1977, Mackie 1984). Como resultado de la variación de algunos de los factores antes mencionados se pueden producir ciclos gametogénicos anuales, semianuales, o continuos (Sastry 1979); aunque no está completamente clara la forma en que dichos factores regulan la sincronización del desarrollo gametogénico de las especies (Sastry 1979, Pearse et al. 1971).

Evidencias aportadas por Giese (1959) indican que las especies que habitan en latitudes altas presentan ciclos reproductivos anuales con desoves principalmente durante primavera-verano, mientras que en latitudes bajas los periodos de desove son largos y pueden ocurrir de forma semianual o continua. De acuerdo a estas evidencias, las especies cuyas poblaciones habitan en la zona norte de Chile, debieran exhibir un ciclo reproductivo semianual o continuo mientras que aquellas ubicadas en la zona sur-austral debieran reproducirse de manera estacional y solo una vez en el año. Esta idea desarrollada por Giese (1959) puede ser puesta a prueba mediante el estudio del ciclo reproductivo de una especie en localidades diferentes ubicadas a cierta distancia una de otra.

Perumytilus purpuratus (Lamarck, 1819) conocido comúnmente como chorito maico (Chile) o choro (Perú), habita regularmente en la zona media del intermareal rocoso de la costa de Chile, y se distribuye desde el Ecuador hasta el Estrecho de Magallanes en el Océano Pacífico y continuando por la costa atlántica argentina hasta Santa Cruz (Osorio \& Bahamonde 1968). Esta especie se encuentra formando densas matrices tridimensionales en la franja media intermareal para incrementar su protección frente al efecto mecánico de las olas, convirtiéndose en un competidor dominante del sustrato primario en la zona central rocosa de Chile (Alvarado \& Castilla 1996, Guiñez 1996).

Desde el punto de vista reproductivo, $P$. purpuratus ha sido descrita como una especie gonocórica, que exhibe fecundación externa y cuyos ovocitos son los de mayor tamaño $(128+9 \mu \mathrm{m})$, entre los mitílidos chilenos; además presenta una larva presuntamente planctotrófica de 14 días (Osorio \& Bahamonde 1968, Ramorino \& Campos 1979). Sin embargo, Garrido (1996) comprobó la lecitotrofia larval en esta especie de forma experimental.

Información de tipo preliminar relacionada con el proceso reproductivo de esta especie en la localidad del Tabo (zona central de Chile) fue reportada por Lozada \& Reyes (1981). En el citado estudio, los autores concluyen que $P$. purpuratus consigue la madurez sexual durante el primer año de vida, cuando su longitud alcanza entre los 8 a $10 \mathrm{~mm}$. Además, de acuerdo a los postulados de Giese (1959) se describe la ocurrencia de un ciclo gametogénico anual teniendo un máximo de emisión gamética a finales de agosto y otro a comienzos de abril. Sin embargo, no existe información de $P$. purpuratus sobre aspectos tales como la sincronización para el desove y la variación latitudinal de periodos de desoves, entre otros aspectos reproductivos.

El propósito del presente estudio fue determinar el ciclo reproductivo de forma cuantitativa y cualitativa en poblaciones de $P$. purpuratus situadas en dos localidades del norte de Chile, con la finalidad de establecer si existen variaciones latitudinales en el patrón de desoves de la especie y luego comparar dichos resultados con los reportados en estudios previos en latitudes mayores. Además, aporta conocimiento sobre el potencial gametogénico de $P$. purpuratus, determinando el porcentaje de ovocitos maduros y su relación con la condición reproductiva de los ejemplares (índice gonadal). Para ello se utilizó metodología de análisis de imágenes para establecer el volumen de la fracción gamética.

\section{Material y métodos}

\section{Muestreo}

Ejemplares machos y hembras adultos de Perumytilus purpuratus fueron recolectados al azar en el intermareal rocoso de las localidades de Taltal (2524'S; 70²8' W) y Huasco (28 $27^{\prime}$ 's; $71^{\circ} 13^{\prime} \mathrm{W}$ ) en el norte de Chile (Fig. 1). Los muestreos fueron realizados con una frecuencia mensual y se extendieron entre octubre de 2007 y octubre de 2008. Los individuos fueron mantenidos vivos en agua de mar y a baja temperatura, para su traslado al Laboratorio de Embriología de la Universidad Austral de Chile en Valdivia.

\section{Análisis del índice gonadal (IG)}

Para estimar el índice gonadal (IG), en cada localidad se utilizaron mensualmente entre 28 y 30 ejemplares de chorito maico. Se removió el tejido blando de las valvas, determinando el sexo y se registró el peso fresco completo ( \pm 0,1 g). Ambos lóbulos gonadales fueron disecados y pesados $( \pm 0,1 \mathrm{~g})$ para determinar el peso fresco gonadal. El IG individual se obtuvo dividiendo el peso fresco gonadal por el peso fresco del tejido blando completo y se multiplicó por 100 . Una vez conocido el sexo de los 


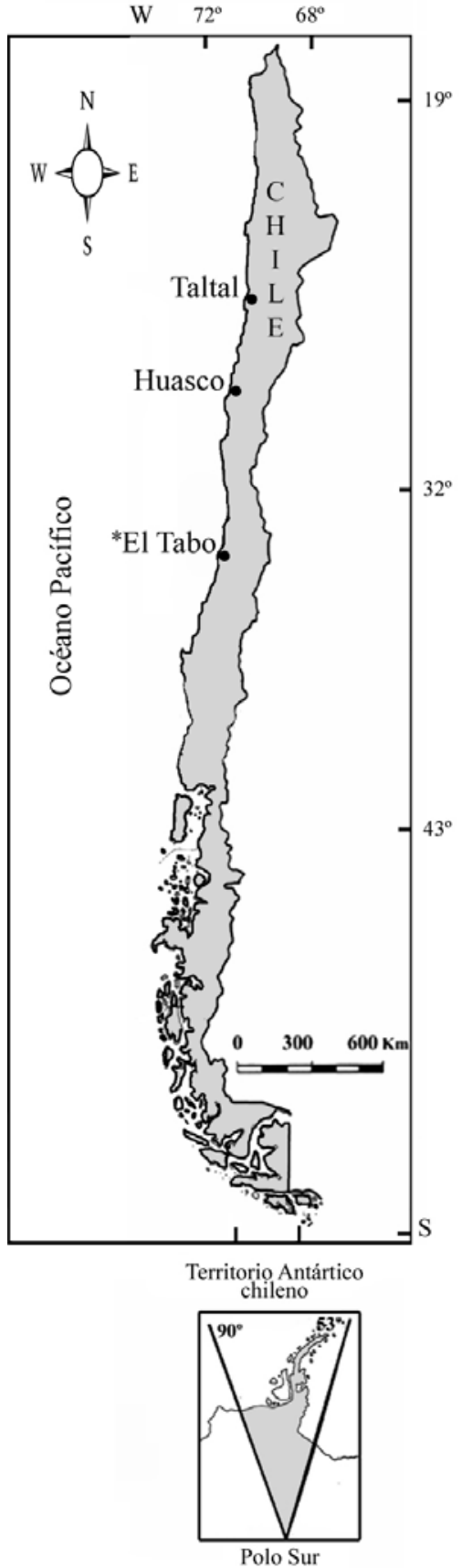

Figura 1

Localidades de muestreo para el estudio del ciclo reproductivo de Perumytilus purpuratus en el norte de Chile. (*) Localidad de muestreo del estudio de Lozada \& Reyes (1981) en Perumytilus purpuratus

Sampling locations for the study of the reproductive cycle of Perumytilus purpuratus in the northern Chile. (*) Sampling location for the study of Lozada \& Reyes (1981) in Perumytilus purpuratus ejemplares, se determinó el IG para machos (IGM) y para hembras (IGH). Con la finalidad de asociar las variaciones del IG con los eventos de desove, se puso a prueba el criterio de Akaboshi \& Illanes (1983) quienes proponen que valores del IG medios o altos seguidos de valores menores indican la presencia de desoves.

\section{Técnica histológica}

De cada ejemplar de chorito maico se extrajo un trozo de la región media de la gónada y se fijó en formalina al 5\%. Las muestras se deshidrataron usando una serie ascendente de concentraciones de etanol, posteriormente fueron aclaradas en butanol e incluidas en parafina histológica, para finalmente ser cortadas en secciones de $7 \mu \mathrm{m}$ de espesor, de forma transversal al eje del lóbulo de la gónada. Las secciones fueron teñidas con Hematoxilina-Eosina (Humason 1962). Para cada ejemplar se obtuvo un portaobjeto con 20 secciones seriadas de gónada.

\section{Estadios gonadales}

La descripción del ciclo gonadal representa la división de la gametogénesis de $P$. purpuratus en diferentes estadios, en forma cualitativa (Tabla 1). La metodología se basa en las observaciones microscópicas de los cortes, utilizando los criterios y categorías descritas por Lozada \& Reyes (1981), Malachowsky (1988), Jaramillo et al. (1993), Jaramillo \& Navarro (1995), Avellanal et al. (2002) y Toro et al. (2002), como referencia.

\section{Volumen de la fracción gamética (VFG)}

El tejido del manto de los mitílidos esta compuesto por tejido conectivo o interfolicular, y folículos conteniendo las células germinales (Lowe et al. 1982). Sin embargo, para aplicar una técnica estereológica es importante que la sección del tejido analizado sea representativa de la totalidad del tejido gonadal (Lowe et al. 1982). Bayne et al. (1985) determinaron que la gónada de los mitílidos es homogénea en relación a la distribución de las células germinales; en base a dicho criterio y para determinar cuantitativamente la fracción de gónada que efectivamente es utilizada para la reproducción (VFG), se aplica la técnica microscópica estereométrica (Weibel \& Gómez 1962, Weibel 1969), que utiliza un retículo de 42 puntos dibujados sobre el ocular de un microscopio. Este reticulado fue copiado y posteriormente ampliado e impreso sobre una lámina de plástico transparente (Jaramillo 2001).

Para la estimación del VFG se procedió a escoger una sección representativa de cada uno de los ejemplares muestreados. Mediante fotografía digital se capturó una 
Tabla 1

Principales características histológicas de los diferentes estados de madurez gonadal

Main histological characteristics for the different gonad maturity stages

\begin{tabular}{|c|c|}
\hline Hembra & Macho \\
\hline $\begin{array}{l}\text { En desarrollo: } \\
\text { Se caracteriza por la presencia de ovocitos en } \\
\text { diferentes estados de desarrollo adosados a la } \\
\text { pared del folículo a través del pedúnculo. } \\
\text { Principalmente ovocitos previtelogénicos y } \\
\text { vitelogénicos y menor cantidad de gonias y } \\
\text { ovocitos maduros. Tejido conectivo soportando los } \\
\text { folículos. }\end{array}$ & $\begin{array}{l}\text { En desarrollo: } \\
\text { Presencia de tejido conjuntivo notable y acinos en } \\
\text { crecimiento. En su interior se identifican una gran } \\
\text { cantidad de espermatogonias en la periferia y } \\
\text { espermatocitos I y II en dirección al lumen. } \\
\text { Presencia de algunas espermátides. }\end{array}$ \\
\hline $\begin{array}{l}\text { Maduro: } \\
\text { Los folículos se encuentran ocupando la mayor } \\
\text { parte del manto. Estos contienen principalmente } \\
\text { ovocitos maduros desprendidos de la pared } \\
\text { folicular. El tejido interfolicular es casi inexistente. }\end{array}$ & $\begin{array}{l}\text { Maduro: } \\
\text { El folículo crecido ocupa todo el manto. En su } \\
\text { interior se encuentra una gran abundancia de } \\
\text { espermatozoides maduros y una baja cantidad de } \\
\text { espermatogonias periféricas. }\end{array}$ \\
\hline $\begin{array}{l}\text { Desove: } \\
\text { Los folículos se encuentran parcialmente } \\
\text { descargados, con presencia de ovocitos maduros, } \\
\text { denotándose rupturas en la pared. Reaparece el } \\
\text { tejido interfolicular en conjunto con algunas } \\
\text { células fagocíticas. }\end{array}$ & $\begin{array}{l}\text { Desove: } \\
\text { El folículo se encuentra reducido, apareciendo } \\
\text { tejido interfolicular junto a células fagocíticas. } \\
\text { Aparecen residuos de espermatozoides en } \\
\text { reabsorción. }\end{array}$ \\
\hline $\begin{array}{l}\text { Post desove: } \\
\text { La característica principal es la gran cantidad de } \\
\text { tejido conjuntivo y la reducción de los folículos. } \\
\text { En su interior se encuentran vacíos con restos } \\
\text { celulares degradados que serán reabsorbidos. } \\
\text { Presencia de amebocitos. }\end{array}$ & $\begin{array}{l}\text { Post desove: } \\
\text { Los folículos están reducidos en tamaño y aparece } \\
\text { una mayor cantidad de tejido conjuntivo con } \\
\text { células fagocíticas. El lumen del acino se } \\
\text { encuentra vacío apareciendo primeros indicios de } \\
\text { espermatogénesis. }\end{array}$ \\
\hline
\end{tabular}

secuencia completa de la gónada en estudio con una resolución de 10x. Las secciones histológicas fueron observadas con un microscopio binocular Carl Zeiss ${ }^{\circledR}$ modelo KF2, y una cámara digital Canon ${ }^{\circledR}$ modelo Powershot A410. Para el análisis de las secciones gonadales se sobrepuso el retículo impreso sobre la imagen de la gónada en el monitor del computador, procediendo a contar el número de ovocitos presentes en cada uno de los diferentes estados reproductivos además de los tejidos anexos. El total de puntos acertados en cada categoría se dividió por 42 y se multiplicó por 100 , obteniéndose así el porcentaje de cobertura para cada tipo de ovocito. El VFG se obtuvo para cada hembra según las siguientes definiciones de los estadios de desarrollo de los ovocitos y tejidos anexos: a) Ovocito previtelogénico: célula germinal adosada a la pared del folículo, cuyo tamaño fluctúa entre 15 y 20 $\mu \mathrm{m}$ de diámetro. Se distingue un núcleo, un nucléolo, una muy reducida y en ocasiones casi inexistente, carga vitelina citoplasmática.

b) Ovocito vitelogénico: célula germinal que puede alcanzar hasta $120 \mu \mathrm{m}$ de diámetro aproximadamente. Se encuentra en la periferia del folículo siempre conectado a la pared interior folicular.

c) Ovocito maduro: es una célula que ha alcanzado su máximo desarrollo y por ende se ha desprendido de la pared folicular; se encuentra en el lumen del acino en condiciones óptimas para el desove. Su tamaño promedio es de 129, $6 \pm$ 5,4 $\mu$ m de diámetro. Además se puede observar el núcleo y el nucléolo, en condiciones óptimas histológicas. 
d) Tejido conjuntivo o interfolicular: tejido adiposo en el cual se encuentran ubicados los acinos gonadales. En este tejido es posible encontrar células fagocíticas o amebocitos durante los periodos de desove y post desove.

e) Otros tejidos y espacios: esta categoría considera ovocitos residuales post desove, que no tienen las características morfológicas óptimas, por lo que no fueron emitidos y presumiblemente serán reabsorbidos, trabéculas, pared folicular y espacios libres como consecuencia de la técnica histológica.

\section{Análisis estadístico}

Los resultados del índice gonadal (IG) y volumen de la fracción gamética (VFG) se expresan como el promedio + 1 error estándar de la media (SE). La prueba de Chi cuadrado se usó para determinar la bondad de ajuste de las proporciones sexuales con la relación esperada de 1:1. Para determinar las diferencias del IG promedio se aplicó un análisis de varianza de una vía (ANDEVA) (Sokal \& Rohlf 1995) y un análisis a posteriori de Tukey $(\alpha=0,05)$ (Day \& Quinn 1989) para así comparar el promedio del índice gonadal con los estados gametogénicos. Además, para determinar las diferencias del IG promedio se aplicó un análisis de varianza de tres vías (ANDEVA) con tres factores fijos principales (Sitio, Sexo y Mes) y a posteriori se aplicó el procedimiento de SLICE para comparar el promedio del índice gonadal, en aquellas interacciones que resultaran significativas.

Para poner a prueba las presunciones de normalidad de los datos se uso la prueba de Kolmogorov-Smirnov corregido por Lilliefors, y para las presunciones de homogeneidad de varianzas se aplicó la prueba de Levene.

La relación entre el porcentaje de ovocitos maduros y el índice gonadal se analizó usando un modelo de regresión lineal simple (Sokal \& Rohlf 1995). Todos los análisis se realizaron usando SAS v. 9.0 (SAS Institute Inc.), MINITAB v. 14.0 (Minitab Inc.) y SPSS v.15.0.1. (SPSS Ibérica, IBM Company).

\section{Resultados}

En total se analizaron 299 choritos adultos provenientes de Huasco, cuyo largo de la concha fluctúo entre 25,46 y $37,60 \mathrm{~mm}$, y 310 choritos adultos provenientes de Taltal cuyas longitudes fluctuaron entre 12,26 y 39,90 mm.

\section{Proporción sexual}

En la localidad de Huasco los machos excedieron en número a las hembras. De un total de 299 individuos muestreados 171 (57,19\%) fueron machos y 128 $(42,81 \%)$ fueron hembras. La proporción sexual (1,34M:1H, $\mathrm{n}=299)$ difirió significativamente de la proporción esperada de 1:1 $(P=0,013)$. En cambio, en Taltal, de un total de 310 individuos muestreados, 155 (50\%) fueron machos y 155 (50\%) hembras. La proporción sexual $(1 \mathrm{M}: 1 \mathrm{H}, \mathrm{n}=310)$ no difirió significativamente de la proporción esperada de 1:1 ( $P=$ 1). En la población muestreada en Huasco se detectó la presencia de un individuo parasitado por tremátodos, presuntamente Proctoeces lintoni.

\section{Índice gonadal}

El índice gonadal de los machos (IGM = 14.901 \pm 0,340 EE) fue superior al de las hembras (IGH = $13.905 \pm$ $0,331)$, esta tendencia fue estadísticamente significativa ( $P=0,0245$; Tabla 4; ANDEVA de tres vías; Fig. 2, y no se observó una interacción significativa de Sexo con los otros dos factores principales Sitio y Mes $(P>0,36$; Tabla 4).

En el caso de la población de Taltal, los índices IGM e IGH siguen un patrón bastante similar durante el periodo estudiado con valores crecientes desde diciembre 2007 a junio de 2008, seguidos de una reducción en julio de 2008 y una recuperación en agosto-septiembre de 2008, finalizando en una abrupta caída en octubre de 2008 (Fig. 2A).

La comparación de los valores porcentuales de IGM e IGH en Taltal, muestran que el IGM es levemente superior entre octubre-noviembre de 2007; similar al IGH en diciembre 2007 y superior entre enero y julio 2008. Sin embargo, durante agosto de 2008 el IGH es superior, pero en los meses siguientes (septiembre y octubre 2008) el IGM nuevamente vuelve a ser mayor (Fig. 2A).

En Huasco es posible observar que las fluctuaciones del IGM y el IGH manifiestan una tendencia similar a lo observado en Taltal. Los valores porcentuales de IGM e IGH crecen desde diciembre 2007 a agosto de 2008, seguido de una caída en septiembre y una rápida recuperación para octubre de 2008 (Fig. 2B). El quiebre en la tendencia al crecimiento de ambos índices puede ser interpretada como el inicio de un proceso de liberación gamética.

El análisis comparativo de los valores porcentuales de IGM e IGH en los choritos de Huasco, muestran que durante todo el periodo estudiado el IGM fue superior, aunque la diferencia más notoria se observa en el periodo diciembre 2007- julio de 2008.

Las diferencias del índice de condición (IG) entre ambas localidades durante los meses muestreados son 

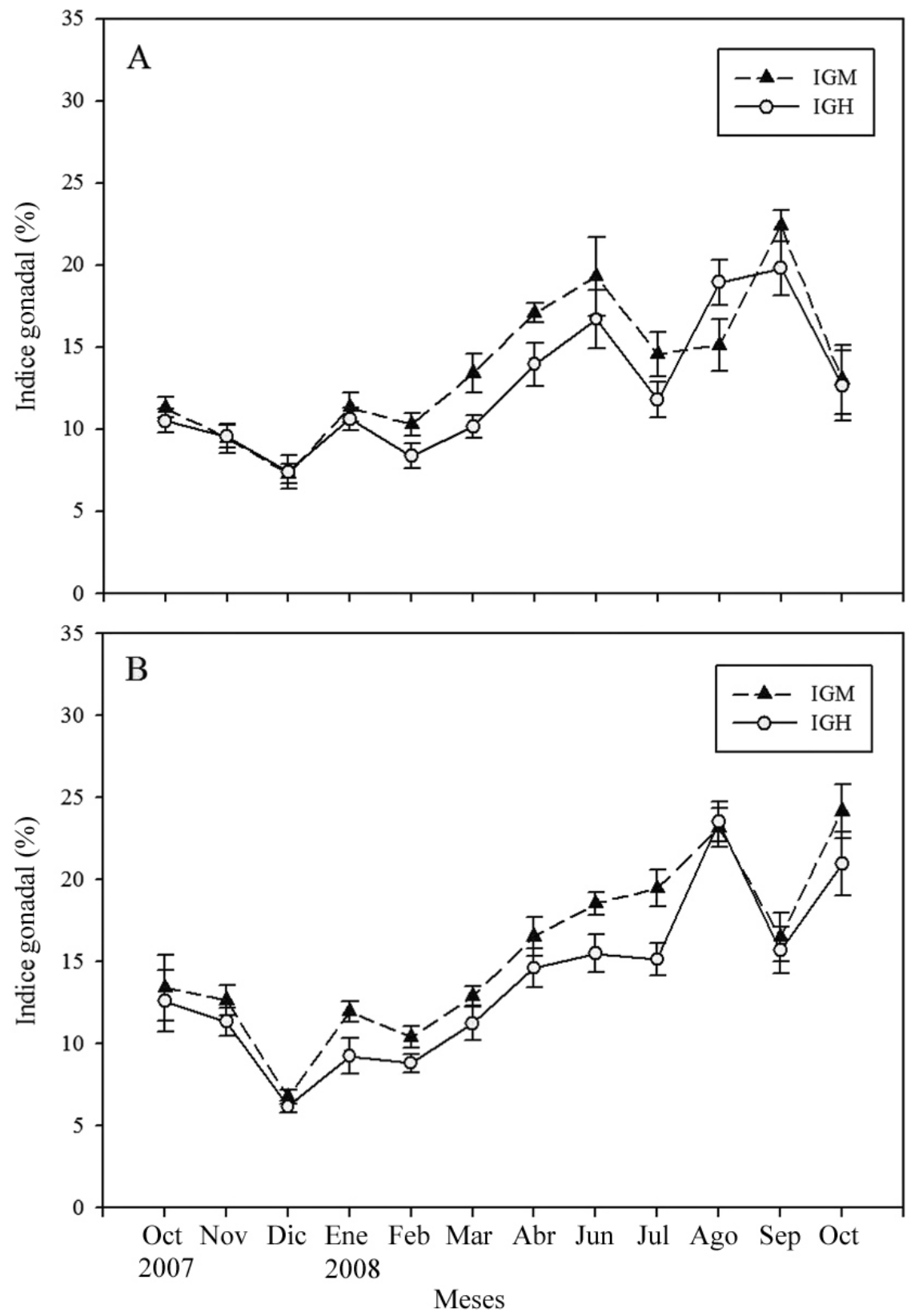

Figura 2

Índice gonadal (Media \pm EE) para machos (IGM) y hembras (IGH) de Perumytilus purpuratus en las localidades de A) Taltal y B) Huasco, entre octubre 2007 y octubre 2008

Gonadic Index (Average \pm SE) for males (MGI) and females (FGI) of Perumytilus purpuratus at the localities of A) Taltal and B) Huasco, between October 2007 and October 2008 

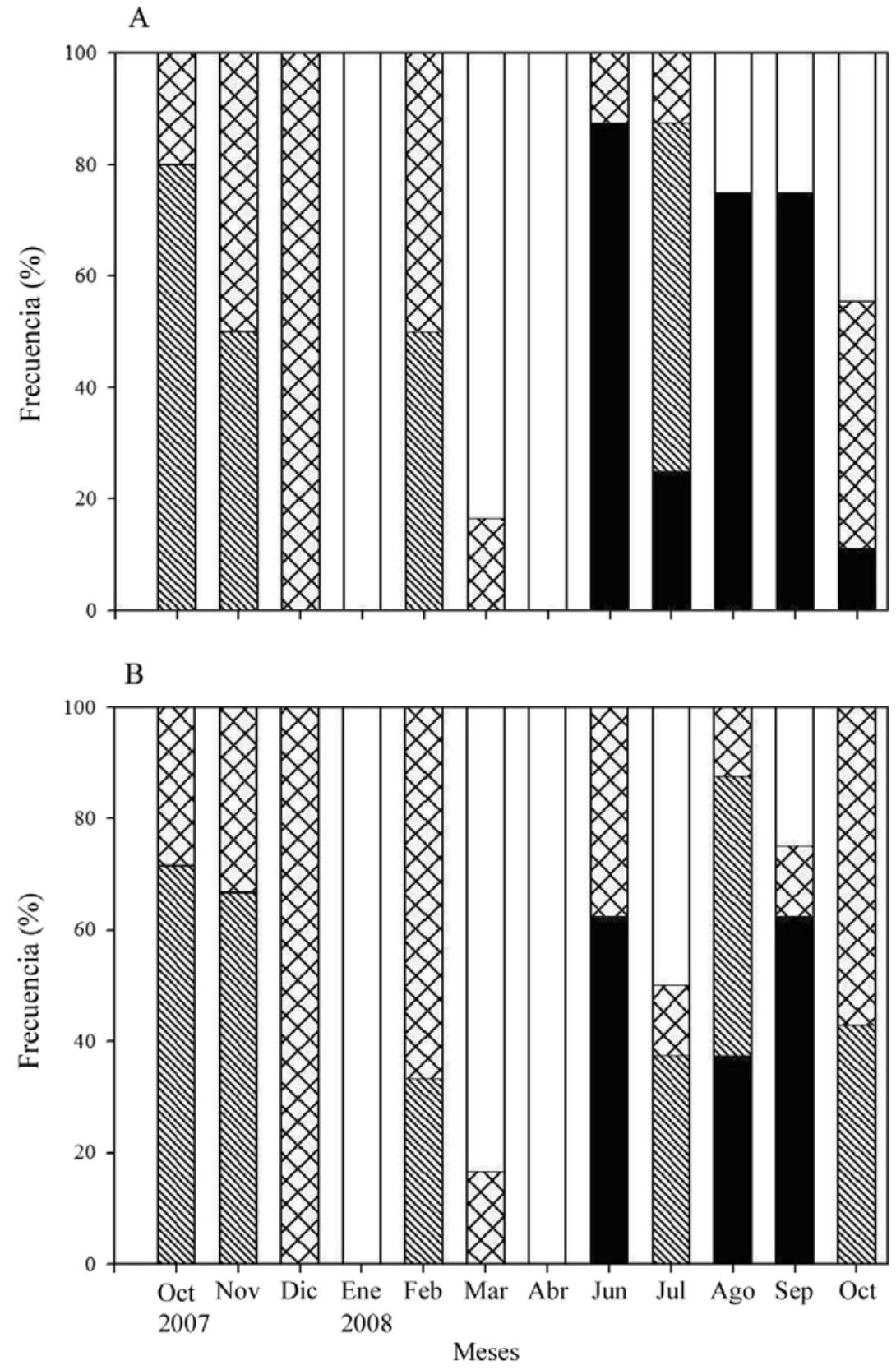

Figura 3

Frecuencia de los estados de maduración gonadal en A) hembras y B) machos de Perumytilus purpuratus entre octubre 2007 y octubre 2008 en la localidad de Taltal, Chile

Frequency of gonadal maturation stages in A) females and B) males of Perumytilus purpuratus between October 2007 and October 2008 at the locality of Taltal, Chile 
asignables a las diferencias significativas observadas para la interacción de Sitio con Mes $(P=0,0002$, Tabla 4). Estas se reflejan en el procedimiento de SLICE (Tabla 5), para los meses de noviembre de 2007, junio, julio, agosto, septiembre y octubre de 2008, periodos de mayor actividad reproductiva.

\section{Ciclo gametogénico}

La población de hembras de Taltal exhibió el estado de desove en tres períodos: octubre-noviembre de 2007, febrero y julio de 2008 (Fig. 3A). En tanto los machos tienen un prolongado período de desove, encontrándose las mayores frecuencias durante octubre y noviembre de 2007 (Fig. 3B).

El estado postdesove en hembras y machos, caracterizado por la casi inexistencia de ovocitos y de espermatozoides respectivamente, exhibió su mayor frecuencia, en diciembre de 2007 y febrero de 2008.

Durante enero y abril de 2008, el 100\% de los individuos tanto hembras como machos presentaron desarrollo gametogénico. Una similar situación sincrónica de desarrollo gonadal se registró en los meses de marzo, abril y septiembre de 2008.

Hembras con folículos maduros se encontraron entre junio y octubre de 2008, denotando su mayor frecuencia en el mes de junio, para ambos sexos (Fig. 3A y 3B). Mientras que machos maduros se observaron en dos periodos: junio de 2008 y agosto-septiembre de 2008.

La población de hembras de $P$. purpuratus de Huasco exhibió individuos maduros durante los periodos octubrenoviembre de 2007, junio-agosto de 2008 y octubre de 2008 (Fig. 4A), mientras que machos con presencia de espermatozoides maduros se observaron en octubre de 2007, entre abril y agosto de 2008 y durante octubre de 2008 (Fig. 4B). Ambos sexos presentaron el mayor porcentaje de individuos maduros en agosto de 2008 (85\%). El periodo de madurez en $P$. purpuratus, fue más prolongada en la población de machos y hembras de Huasco que el observado en Taltal.

En el caso de individuos en desove, se pudieron distinguir tres períodos en los cuales más del 50\% de hembras se encontraron en este estado en el área de Huasco, correspondiendo a los meses de noviembre de 2007, enero de 2008 y la máxima frecuencia observada fue en septiembre de 2008 (87,5\%). Los machos tuvieron sus máximas frecuencias de desove en noviembre de 2007 (83,3\%) y septiembre de 2008 (75\%). Tanto machos y hembras en estado postdesove alcanzaron máximas frecuencias, con un $100 \%$ y $88,9 \%$ respectivamente en diciembre de 2007.

La población de Huasco presentó desarrollo gametogénico entre enero y julio de 2008 distinguiéndose en marzo el mayor porcentaje de estos con un $100 \%$ de la población de machos y de hembras.

En ambas localidades estudiadas se registraron desoves invernales. En Huasco sucedió en agosto (12,5\% hembras; $12,5 \%$ machos) y en Taltal se registró en julio (62,5\% hembras; $37,5 \%$ machos).

Se observaron asincronías en el desove en ambas poblaciones. En Taltal se presentó en los machos en agosto y octubre de 2008 y en Huasco la asincronía se reflejó en las hembras en los meses de diciembre de 2007 y enero de 2008 y en machos en octubre de 2008.

En Huasco el 100\% de la población muestreada (machos y hembras) se encontró en desarrollo en marzo de 2008 , decreciendo hasta llegar a un $0 \%$ en agosto de 2008, mismo período donde aumentaron los machos maduros.

\section{Volumen de la fracción gamética}

Tanto para las poblaciones de Huasco como Taltal, los folículos ováricos fueron dominados por la presencia de ovocitos vitelogénicos y maduros durante el periodo muestreado, mientras los ovocitos previtelogénicos exhibieron una baja frecuencia porcentual durante el mismo periodo.

En Taltal, la frecuencia de ovocitos previtelogénicos aumentó entre octubre de 2007 y enero de 2008; para luego en febrero comenzar a decaer hasta septiembre de 2008 y recuperarse nuevamente en octubre de 2008.

El porcentaje de ovocitos vitelogénicos decreció entre octubre y diciembre de 2007 para luego iniciar un periodo de recuperación que se extendió hasta agosto de 2008, mes en el que se alcanzó la mayor frecuencia en el periodo muestreado.

El porcentaje de ovocitos maduros decreció en cuatro ocasiones durante el periodo muestreado sugiriendo con ello periodos de desoves: entre octubre y diciembre de 2007 (desove primaveral tardío), febrero y marzo de 2008 (desove otoñal), y entre junio y julio (desove invernal). La caída mas notoria en los porcentajes de ovocitos maduros ocurrió entre septiembre y octubre de 2008 (desove primaveral) (Fig. 5A).

El tejido interfolicular o conjuntivo tuvo sus máximos porcentajes (sobre el $35 \%$ de frecuencia) en diciembre de 2007 y marzo de 2008, cuando se observó una disminución en la frecuencia de ovocitos vitelogénicos y maduros (Fig. 5A y 5B). La categoría de otros tejidos en donde se encuentran los ovocitos residuales, registraron dos máximo importantes durante enero y abril de 2008, inmediatamente después de los desoves descritos (Fig. 5B). 

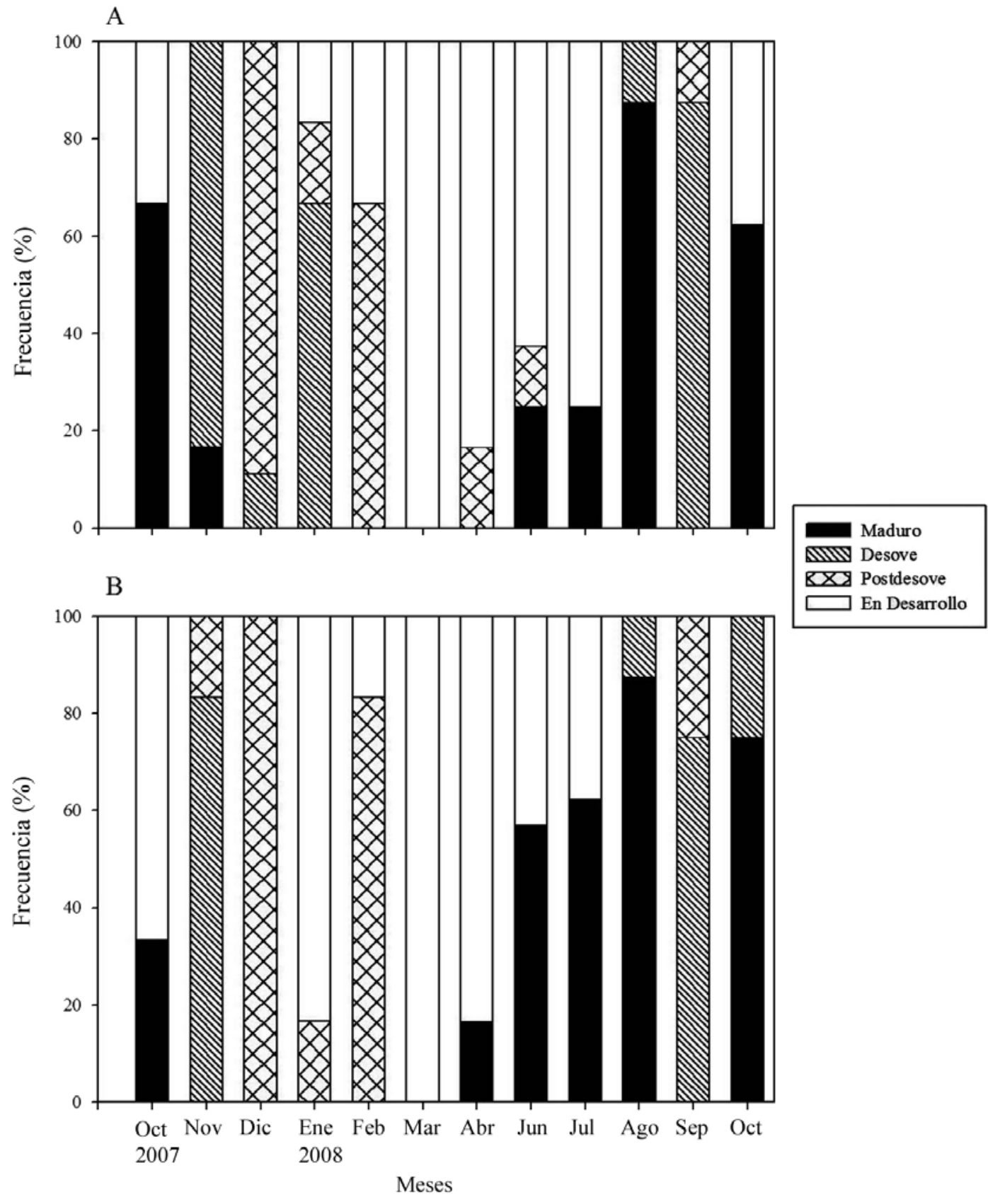

Figura 4

Frecuencia de los estados de maduración gonadal en A) hembras y B) machos de Perumytilus purpuratus entre octubre de 2007 a octubre de 2008 en la localidad de Huasco, Chile

Frequency of gonadal maturation stages in A) females and B) males of Perumytilus purpuratus between October 2007 and October 2008 at the locality of Huasco, Chile 

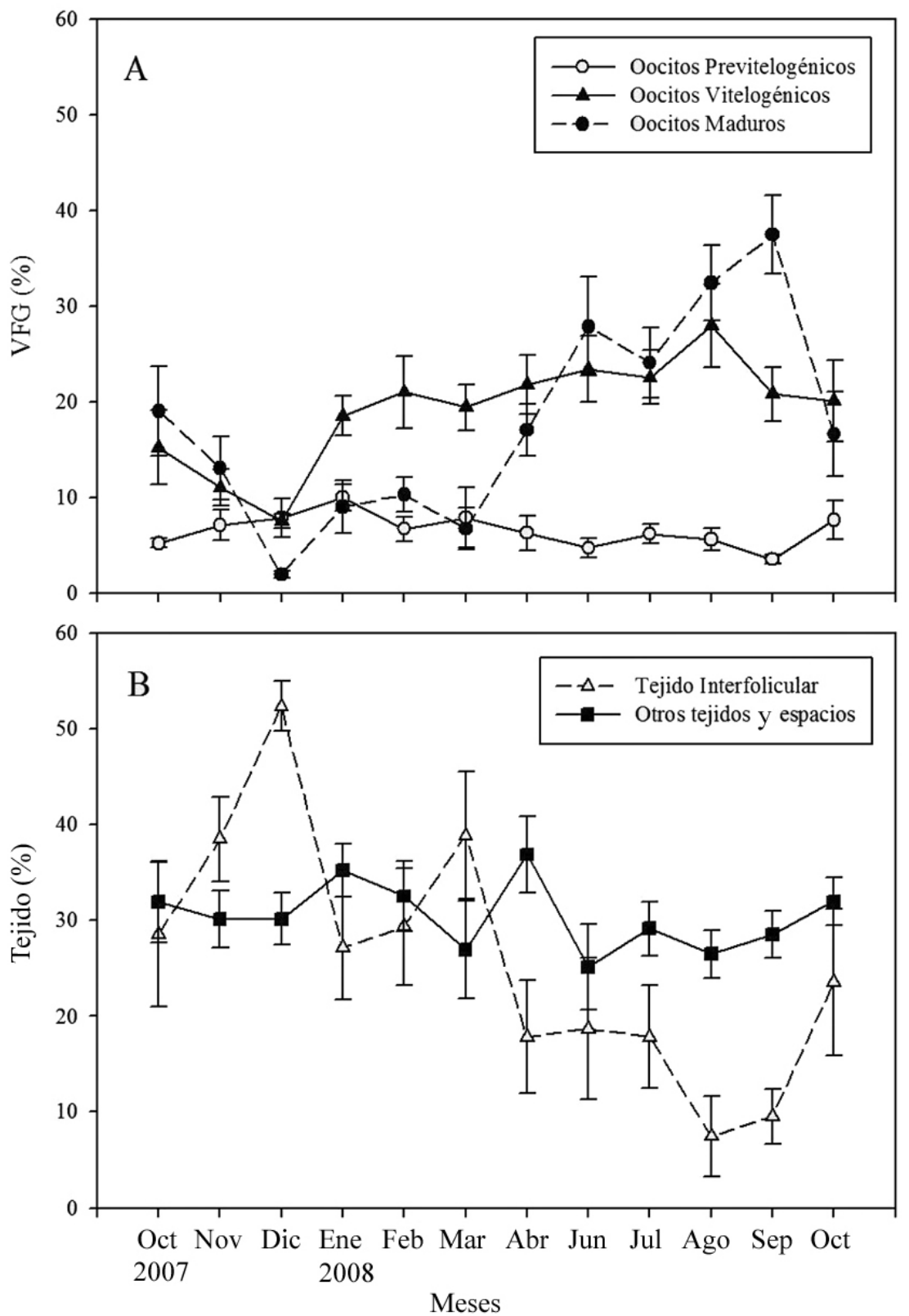

Figura 5

A) Volumen de la Fracción Gamética (VFG) para ovocitos previtelogénicos, ovocitos vitelogénicos y ovocitos maduros y B) el porcentaje de tejido interfolicular y otros espacios (media \pm EE) en la localidad de Taltal, Chile, entre octubre 2007 y octubre 2008

A) Gametic Volume Fraction (GVF) for previtelogenic oocytes, vitelogenic oocytes and mature oocytes and

B) percentage of interfolicular connective tissue and other spaces (Average $\pm \mathrm{SE}$ ) at the locality of Taltal, Chile, between October 2007 and October 2008 
El porcentaje de ovocitos previtelogénicos en Huasco tuvo su mayor frecuencia a finales de diciembre de 2007 (Fig. 6A), mismo periodo en el cual se registró el menor porcentaje de ovocitos maduros y vitelogénicos. A partir de dicho mes los porcentajes de ovocitos previtelogénicos decrecieron en los restantes meses de muestreo (enerooctubre de 2008).

Los porcentajes de ovocitos maduros y vitelogénicos mostraron una tendencia a fluctuar de manera similar durante el periodo de muestreo. En el caso de los ovocitos vitelogénicos entre octubre y diciembre de 2007 decrecieron presentando en este último mes su frecuencia más baja. Para enero de 2008 el porcentaje de ovocitos vitelogénicos y maduros aumentó pero decayó de inmediato en febrero de 2008. A partir de marzo se inicia una clara recuperación en la frecuencia de ovocitos vitelogénicos y maduros alcanzando los valores más altos para los ovocitos vitelogénicos en abril de 2008.

La frecuencia de ovocitos maduros decreció considerablemente entre octubre y diciembre de 2007, presentando a finales de este mes el menor porcentaje (Fig. 6A), sugiriendo el desove más importante del muestreo. Siguiendo a esta caída hubo una leve recuperación en enero que decayó nuevamente en febrero de 2008. A partir de marzo y hasta comienzos de agosto de 2008 se produjo un aumento sostenido en la frecuencia de ovocitos maduros alcanzando el máximo valor registrado para la frecuencia (38,9\%), lo que concluyó en septiembre de 2008 cuando se produjo la caída de la frecuencia sugiriendo un nuevo desove.

El porcentaje de tejido interfolicular mostró elevados valores durante diciembre de 2007, febrero y julio de 2008 siendo dichos valores iguales en diciembre de 2007 y julio de 2008, pero superiores durante febrero de 2008, a la categoría de ‘otros tejidos'. Estas frecuencias indican que hubo una disminución de la cantidad de acinos reproductivos femeninos. Del mismo modo, se observó que entre diciembre y agosto de 2008 decreció la categoría de ‘otros tejidos y espacios' coincidente con el aumento del porcentaje de ovocitos vitelogénicos y maduros (Fig. 6B).

\section{Estados gametogénicos e índice gonadal}

Para relacionar el índice gonadal (IG) con los estados gametogénicos se realizó un ANOVA de una vía para cada población. En Huasco el estado gametogénico maduro obtuvo el mayor promedio de IG, seguido del estado en desarrollo, desove y con la media más baja el postdesove (Tabla 2). Para Taltal también el estado gametogénico maduro registró el mayor promedio de IG, seguido de los estados desove, en desarrollo y postdesove.

Tabla 2

Promedio del índice gonadal (con su desviación estándar entre paréntesis) para los cuatro estados gametogénicos en los sitios de estudio. Resumen del ANOVA (ver Material y métodos) y del resultado del test de Tukey

Mean of the gonadic Index (with its standard deviations in parentheses) for the four gametogenic stages at the study sites. Summary of the ANOVA (see Material and Methods) and of result of Tukey's test

\begin{tabular}{|c|c|c|c|c|c|}
\hline \multirow{2}{*}{ Localidad } & \multirow{2}{*}{$\begin{array}{c}\text { Estado } \\
\text { Gametogénico }\end{array}$} & \multirow{2}{*}{$\begin{array}{l}\text { Promedio del IG } \\
\qquad(\%)\end{array}$} & \multicolumn{2}{|c|}{ ANOVA } & \multirow{2}{*}{ Tukey } \\
\hline & & & $\mathrm{F}$ & $P$ & \\
\hline \multirow{4}{*}{ Taltal } & Maduro & $21,91(4,41)$ & \multirow[t]{4}{*}{71,95} & \multirow[t]{4}{*}{0,001} & A \\
\hline & En desarrollo & $14,31(3,47)$ & & & B \\
\hline & Desove & $12,79(4,48)$ & & & B \\
\hline & Post desove & $9,30(3,15)$ & & & $\mathrm{C}$ \\
\hline \multirow{4}{*}{ Huasco } & Maduro & $20,39(5,07)$ & \multirow[t]{4}{*}{47,04} & \multirow[t]{4}{*}{0,001} & A \\
\hline & Desove & $15,43(4,75)$ & & & B \\
\hline & En desarrollo & $14,22(3,77)$ & & & B \\
\hline & Post desove & $8,41(2,84)$ & & & $\mathrm{C}$ \\
\hline
\end{tabular}



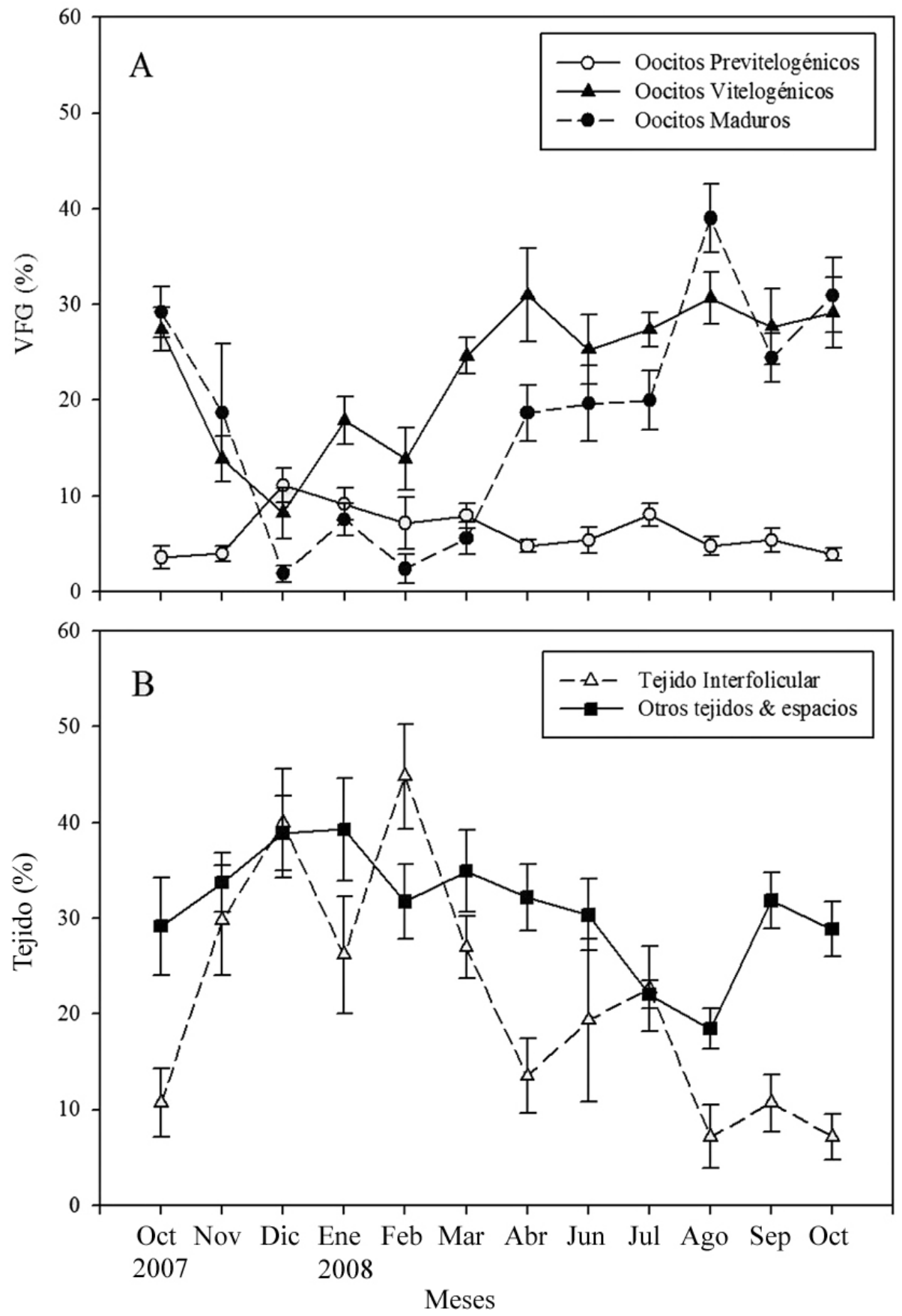

Figura 6

A) Volumen de la Fracción Gamética (VFG) para ovocitos previtelogénicos, vitelogénicos y maduros y B) el porcentaje de tejido interfolicular y otros espacios (media \pm SE) en la localidad de Huasco,

Chile, entre octubre 2007 y octubre 2008

A) Gametic Volume Fraction (GVF) for previtelogenic oocytes, vitelogenic oocytes and mature oocytes and B) percentage of interfolicular connective tissue and other spaces (Average \pm SE) at the locality of Huasco, 


\section{Tabla 3}

\section{Resultados del análisis de regresión entre el porcentaje de ovocitos maduros (\%OM) y el índice gonádico (\%IG) en los sitios de estudio}

Results of the regression analyses carried out between the percentages of mature oocytes $(\% \mathrm{OM})$ and the gonadic index (\%IG) at the study sites

\begin{tabular}{cccc}
\hline Localidad & Ecuación de regresión & r & $P$-valor \\
\hline Taltal & $\% \mathrm{IG}=7,99+0,31 \% \mathrm{OM}$ & 0,72 & 0,001 \\
Huasco & $\% \mathrm{IG}=8,59+0,30 \% \mathrm{OM}$ & 0,73 & 0,001 \\
\hline
\end{tabular}

Tabla 4

Resultados del análisis de varianza de tres vías (Sitio, Sexo y Mes) del índice gonádico de hembras y machos en Taltal y Huasco (* significativo)

Results of the three way analyses of variante (site, sex and month) of the females and males gonadic index at Taltal and Huasco (* significant)

\begin{tabular}{lrrcrc}
\hline FUENTE & DF & SS & MS & F & $P$-valor \\
\hline Sitio & 1 & 0,943 & 0,9434 & 3,58 & 0,0598 \\
Sexo & 1 & 1,351 & 1,3512 & 5,12 & $0,0245^{*}$ \\
Meses & 11 & 78,528 & 7,1389 & 27,06 & $<0,0001^{*}$ \\
Sitio x Sexo & 1 & 0,217 & 0,2168 & 0,82 & 0,3656 \\
Sitio x Meses & 11 & 10,090 & 0,9173 & 3,48 & $0,0002^{*}$ \\
Sexo x Meses & 11 & 3,163 & 0,2875 & 1,09 & 0,3700 \\
Sitio x Sexo x Meses & 11 & 1,805 & 0,1641 & 0,62 & 0,8092 \\
Error & 237 & 62,521 & 0,2638 & & \\
\hline
\end{tabular}

Para ambas localidades (Huasco y Taltal) la correlación de Pearson fue estadísticamente significativa ( $P<0,0001 ; \mathrm{r}>0,72)$ entre las variables porcentaje de ovocitos maduros e índice gonádico (Tabla 3).

\section{Discusión}

La proporción sexual de $P$. purpuratus en Huasco se desvío de la relación esperada 1:1 existiendo un mayor número de machos. Una posible explicación para esta desviación en la proporción esperada surge a partir de la observación de un individuo parasitado por tremátodos en esta localidad. Aitken-Ander \& Levin (1985) reportaron que en el caso de Crepidula convexa los parásitos trematodos infectan preferentemente a hembras; mientras que Osorio \& Castillo (1984) registran también parasitismo solo en las hembras de Venus antiqua. Lasiak (1992) encuentra esporocistos de un trematodo bucefalido que infecta, en el sur de Chile, el manto de Perumytilus purpuratus y que produce castración, indicando además, que el porcentaje de infección en esta especie es de $<1 \%$, lo que puede afectar desfavorablemente el potencial reproductivo de la especie. Loot et al. (2005) determinaron que el tremátodo Proctoeces lintoni completa su ciclo de vida en invertebrados intermareales tales como P. purpuratus y Sicyases sanguineus.

Los antecedentes aquí descritos permiten suponer que el mayor número de machos observados en la zona de Huasco puede ser resultado de un parasitismo selectivo sobre las hembras de $P$. purpuratus. Sin embargo es necesario realizar estudios más acabados respecto del tema ya que la literatura propone que menos del 1\% de la población sería parasitada.

El análisis de los resultados para la variación de los estadios gonadales de la población de la localidad de Taltal indican que $P$. purpuratus tiene un ciclo reproductivo semianual, caracterizado por un desove principal que ocurre durante octubre y noviembre (desove en primavera) y un desove menor en julio (invierno) y febrero (verano), que podría ser explicado por una recuperación acelerada de la gónada como resultado de una oferta alimentaria y temperaturas favorables para la reproducción (Ropes 1968, Sastry 1979, Manzi et al. 1985, Urban \& Campos 1994, Avellanal et al. 2002, Thorarinsdóttir \& Gunnarsson 2003). Sin embargo es muy difícil determinar cuál de ambos factores es el más importante en este proceso (Brockington \& Clarke 2001). En el caso de Huasco, el desove principal ocurre entre noviembre y enero (fines primavera y verano) mientras que el desove menor se presenta en agosto y septiembre (fines de invierno). Las diferencias en las emisiones gaméticas de $P$. purpuratus entre ambas localidades se respalda en los análisis estadísticos basados en el índice gonadal (Tabla 5). Por esto es posible inferir que las condiciones tanto endógenas como exógenas cambiaron tanto en Taltal como en Huasco, provocando diferencias en la actividad gametogénica de esta especie. La asincronía en el desove, entre machos y hembras en ambas poblaciones, se puede atribuir a los procesos de espermatogénesis y ovogénesis en los moluscos, los cuales requieren distintos tiempos de desarrollo (Peredo et al. 1987).

Estos resultados se oponen a lo descrito por Lozada \& Reyes (1981) para una población de la localidad del Tabo (Fig. 1), ubicada novecientos kilómetros al sur de Taltal y a quinientos cincuenta kilómetros de Huasco, donde se reporta que $P$. purpuratus tiene un ciclo anual. Esta diferencia puede ser explicada por ejemplo en base a un gradiente de temperatura latitudinal (Seed 1976). El efecto de la temperatura de las aguas y la latitud parecen estar asociados con la estrategia reproductiva de 
Tabla 5

\section{Resultado del procedimiento de SLICE de las diferencias del índice gonadal (IG) entre ambas poblaciones para cada mes (* diferencias significativas entre ambos sitios; $* *$ diferencias marginalmente significativas)}

Results of the SLICE procedure of the gonadic index (IG) differences between both populations at each month (* significant differences between sites, ** significant marginal differences)

\begin{tabular}{cccccc}
\hline MESES & DF & SS & MS & F & $P$-valor \\
\hline Oct & 1 & 0,186779 & 0,186779 & 0,71 & 0,4009 \\
Nov & 1 & 1,295162 & 1,295162 & 4,91 & $\mathbf{0 , 0 2 7 7 *}^{*}$ \\
Dic & 1 & 0,046185 & 0,046185 & 0,18 & 0,6760 \\
Ene & 1 & 0,381336 & 0,381336 & 1,45 & 0,2304 \\
Feb & 1 & 0,178524 & 0,178524 & 0,68 & 0,4115 \\
Mar & 1 & 0,147217 & 0,147217 & 0,56 & 0,4558 \\
Abr & 1 & 0,040043 & 0,040043 & 0,15 & 0,6972 \\
Jun & 1 & 0,909985 & 0,909985 & 3,45 & $\mathbf{0 , 0 6 4 5}^{\text {*** }}$ \\
Jul & 1 & 1,009296 & 1,009296 & 3,83 & $\mathbf{0 , 0 5 1 6}^{\text {*** }}$ \\
Ago & 1 & 1,648506 & 1,648506 & 6,25 & $\mathbf{0 , 0 1 3 1 *}^{*}$ \\
Sep & 1 & 0,917066 & 0,917066 & 3,48 & $\mathbf{0 , 0 6 3 5}^{\text {*** }}$ \\
Oct & 1 & 4,356737 & 4,356737 & 16,52 & $<\mathbf{0 , 0 0 0 1}^{*}$ \\
\hline
\end{tabular}

las especies, así, zonas circumpolares estarán caracterizadas por poseer especies que presentan un ciclo reproductivo anual, las zonas templadas por especies con ciclos semianuales y las zonas tropicales con especies que se reproducen de manera continua (Rand 1973). Es posible asumir, entonces, que en el Tabo y localidades ubicadas más al sur, se presenta una marcada estacionalidad ambiental que puede generar como resultado ciclos anuales, con gametogénesis durante invierno y desoves durante las estaciones de primavera y/o verano. En contraste, las especies presentes en localidades situadas más al norte que el Tabo (áreas más templadas como Huasco y Taltal) debieran presentar ciclos reproductivos semianuales e incluso continuos. (Heffernan \& Walker 1989, Heffernan et al. 1989a, b).

El periodo de reposo gonadal entre cada ciclo gametogénico, tanto en Huasco como en Taltal, es breve, no prolongándose por más de un mes. Esta rápida recuperación gonadal se puede explicar porque durante este periodo encontramos los mayores porcentajes de ovocitos residuales (otros tejidos), lo que se puede traducir en un incremento en la acumulación de sustancias de reserva. Estos elementos remanentes de la gametogénesis son reabsorbidos y utilizados directamente en la producción de nuevos gametos. Bayne (1976) describe aquellas especies con ciclos claramente marcados como 'especies conservativas', ya que en el desarrollo gonádico éstas utilizan sustancias de reserva previamente almacenadas.

Cuando el porcentaje de ovocitos maduros es bajo, se incrementa el porcentaje de tejido interfolicular o conjuntivo; este tejido es muy importante para el proceso reproductivo porque además de las funciones normales de protección, sostén, nutrición e inmunidad que este tejido tiene (Leeson et al. 1987), se especializa en el almacenamiento de sustancias de reserva, particularmente glucógeno y lípidos neutros. En el caso de los bivalvos, estas sustancias se almacenan en las células de Leydig (Deleón-Rodríguez et al. 1984). Además se ha reportado que también en el manto de los mitílidos se realizan funciones de almacenamiento (Mathieu \& Lubet 1993).

En base a lo descrito por Akaboshi \& Illanes (1983) quienes indican que valores altos del IG seguidos de valores bajos corresponden al inicio de una emisión gamética, los resultados indican que el índice gonadal es un buen indicador de desove para $P$. purpuratus en los sitios estudiados. Al relacionar las variaciones de IG con los porcentajes de ovocitos maduros en ambas localidades, se encontró que hay una correlación directa entre ambos parámetros (Tabla 3), es decir, que a mayor índice gonadal mayor porcentaje de ovocitos maduros.

Por otra parte, el análisis estadístico que relacionó el índice gonadal con los estados gametogénicos determinó que en ambas poblaciones los mayores valores del IG representan el estado gametogénico ‘maduro’ y que los valores menores de IG representaban los estados de desove y postdesove (Tabla 2). Cabe destacar que el índice gonadal es superior en machos, tendencia estadísticamente significativa (Tabla 4) tanto en Taltal como en Huasco.

Finalmente, en este trabajo se logró establecer de manera cuantitativa los periodos en que se produjo la emisión gamética utilizando para ello los porcentajes de ovocitos maduros a través del cálculo del VFG. Así, porcentajes medios altos seguidos de porcentajes medios bajos corresponden a un indicio concreto de desove. En Taltal se determinó que el desove se presenta en primavera-verano (octubre-diciembre), finales del verano (febrero), invierno (junio-julio) y la más importante emisión gamética durante primavera (septiembreoctubre). Las evidencias quedan demostradas en el gráfico de frecuencias para los estados gonadales. En Huasco, los desoves parecen ocurrir en tres ocasiones: primavera (octubre-diciembre), verano (enero-febrero) e invierno (agosto-septiembre). 
Bayne (1976) determina que en muchos bivalvos el periodo de desove está relacionado con la disponibilidad de alimento para el óptimo desarrollo de la progenie, mientras que Wolff (1988) sugiere que las altas temperaturas favorecen el desove, aunque probablemente el factor más crítico es la disponibilidad de alimento. La gametogénesis y el desove de una especie se ven influenciado por un conjunto de variables tanto endógenas como exógenas, por ello no existe un patrón reproductivo específico para los bivalvos, sino mas bien el conjunto de las condiciones ambientales dadas en el lugar donde habita la población, que entregan una periodicidad gametogénica.

\section{Agradecimientos}

Agradecemos al Instituto de Embriología de la Universidad Austral de Chile por su apoyo y asistencia en la técnica estereométrica e histológica. A Valentín Peña por su asesoría en el proceso histológico, a Marcela Riveros por su ayuda en el procesamiento de las muestras y a Fernanda Orellana por el apoyo en el muestreo en terreno. Este trabajo fue financiado por los proyectos FONDECYT 1050848 y 1101007.

\section{Literatura citada}

Aitken-Ander P \& N Levin. 1985. Occurrence of adult and developmental stages of Proctoeces maculatus in the gastropod Crepidula convexa. Transactions of the American Microscopical Society 104: 250-260.

Akaboshi S \& JE Illanes. 1983. Estudios experimental sobre la captación, precultivo y cultivo, en ambiente natural de Chlamys (Argopecten) purpuratus (Lamarck 1819), en bahía Tongoy. Proceedings of the Symposium Internacional de Acuacultura, Coquimbo, Chile, pp. 233-254.

Alvarado JL \& JC Castilla. 1996. Tridimensional matrices of Perumytilus purpuratus on intertidal platforms with varying wave forces in central Chile. Marine Ecology Progress Series 133: 135-141.

Avellanal MH, E Jaramillo, E Clasing, P Quijón \& H Contreras. 2002. Reproductive cycle of the bivalves Ensis macha (Molina, 1782) (Solenidae), Tagelus dombeii (Lamarck, 1818) (Solecurtidae), and Mulinia edulis (King, 1831) (Mactridae) in Southern Chile. The Veliger 45: 3344.

Bayne BL. 1976. Marine mussels: Their ecology and physiology, 506 pp. Cambridge University Press, Cambridge.

Bayne BL, DA Brown, K Burns, DR Dixon, A Ivanovici, DR Livingstone, DM Lowe, MN Moore, AR Stebbing \& J Widdows. 1985. The effects of stress and pollution on marine animals, 384 pp. Praeger, New York.
Brockington S \& A Clarke. 2001. The relative influence of temperature and food on the metabolism of a marine invertebrate. Journal of Experimental Marine Biology and Ecology 258: 87-99.

Day R \& G Quinn. 1989. Statistical comparisons of the treatments after analysis of variance. Ecological Monographs 59: 430-460.

Deleón-Rodríguez I, AJ Pérez-Zapata \& F GarcíaDomínguez. 1984. Descripción morfológica y análisis histoquímico del tejido conjuntivo del ostión Crassostrea virginica (Gmelin). Anales de la Escuela Nacional de Ciencias Biológicas, México 28: 183-191.

Garrido O. 1996. Biología comparada de la reproducción en moluscos Bivalvos Mytilidae. Tesis de Doctorado, Facultad de Ciencias, Universidad Austral de Chile, Valdivia, 68 pp.

Giese AA. 1959. Comparative physiology: annual reproductive cycle of marine invertebrates. Annual Review of Physiology 21: 547-576.

Giese A \& J Pierse. 1977. General principles. En: Giese AC \& JS Pierse (eds). Reproduction of marine invertebrates, pp. 1-49. Academic Press, New York.

Guiñez R. 1996. Dinámica poblacional del chorito maico, Perumytilus purpuratus (Lamarck, 1819) (Bivalvia: Mytilidae), en gradientes de exposición al oleaje. Tesis de Doctorado, Departamento de Ecología, Pontificia Universidad Católica de Chile, Santiago, 213 pp.

Heffernan PB \& RL Walker. 1989. Gametogenic cycles of three bivalves in Wassaw Sound Georgia III. Geukensia demissa (Dillwyn, 1817). Journal of Shellfish Research 8: 327-334.

Heffernan PB, RL Walker \& JL Carr. 1989a. Gametogenic cycles of three marine bivalves in Wassaw Sound, Georgia I. Mercenaria mercenaria (Linnaeus, 1758). Journal of Shellfish Research 8: 51-60.

Heffernan PB, RL Walker \& JL Carr. 1989b. Gametogenic cycles of three marine bivalves in Wassaw Sound, Georgia II. Crassostrea virginica (Gmelin, 1791). Journal of Shellfish Research 8: 61-70.

Humason GL. 1962. Animal tissue techniques, 661 pp. W.H Freeman \& Company, San Francisco.

Jaramillo JR. 2001. The effect of a seasonal pulse of sinking phytodetritus on two benthic deposit-feeding species, Yoldia hyperborea and Ctenodiscus crispatus. Ph D Thesis, Memorial University of Newfoundland, Canada, 384 pp.

Jaramillo JR \& J Navarro. 1995. Reproductive cycle of the Chilean Ribbed Mussel Aulacomya ater (Molina, 1782). Journal of Shellfish Research 14: 165-171.

Jaramillo JR, J Winter, J Valencia \& A Rivera. 1993. Gametogenic cycle of the Chiloe scallop (Chlamys amandi). Journal of Shellfish Research 12: 59-64.

Lasiak T. 1992. Bucephalid trematode infections in mytilid bivalves from the rocky intertidal of Southern Chile. Journal of Molluscan Studies 58: 29-36. 
Leeson CR, TS Leeson \& AA Paparo. 1987. Histología, 618 pp. Interamericana, México.

Loot G, M Aldana \& S Navarrete. 2005. Effects of human exclusion on parasitism in intertidal food webs of Central Chile. Conservation Biology 19: 203-212.

Lowe DM, MN Moore \& BL Bayne. 1982. Aspect of gametogenesis in the marine mussel Mytilus edulis L. Journal of the Marine Biological Association of the United Kingdom 62: 133-145.

Lozada E \& P Reyes. 1981. Reproductive biology of a population of Perumytilus purpuratus at El Tabo, Chile. The Veliger 24: 147-154.

Mackie G. 1984. Bivalves. En: Tompa A, N Verdonk \& J Van den Biggelaar (eds). The Mollusca 7: 351-418. Academic Press, New York.

Malachowsky M. 1988. The reproductive of the rock scallop Hinnites giganteus (Grey) in Humboldt Bay California. Journal of Shellfish Research 7: 341-348.

Manzi J, M Bobo \& V Burrell. 1985. Gametogenesis in a population of the hard clam, Mercenaria mercenaria (Linnaeus), in North Santee Bay, South Carolina. The Veliger 28: 186-194.

Mathieu M \& P Lubet. 1993. Storage tissue metabolism and reproduction in marine bivalves - a brief review. Invertebrate Reproduction and Development 23: 123-129.

Osorio C \& N Bahamonde. 1968. Moluscos bivalvos en las pesquerías chilenas. Biología Pesquera 3: 69-128.

Osorio C \& M Castillo. 1984. Almejas comestibles (Venus antiqua) infectadas por tremátodos. Parasitología al Día 8: 117-118.

Pearse JS, JB MacClintock \& I Bosch. 1991. Reproduction of Antarctic benthic marine invertebrates: tempos, modes, and timing. American Zoologist 31: 65-80.

Peredo S, E Parada \& I Valdebenito. 1987. Gametogenesis and reproductive cycle of the surf clam Mesodesma donacium (Lamarck, 1818) (Bivalvia: Mesodematidae) a Queule Beah, Southern Chile. The Veliger 30: 55-68.

Ramorino L \& B Campos. 1979. Desarrollo larval y postlarval de Perumytilus purpuratus (Lamarck, 1819) Bivalvia: Mytilidae. Anales del Museo de Historia Natural de Valparaíso 12: 207-218.
Rand WM. 1973. A stochastic model of the temporal aspect of breeding strategies. Journal of Theoretical Biology 40: 337351.

Ropes J. 1968. Reproductive cycle of the surf clam Spisula solidissima in offshore New Jersey. The Biological Bulletin 135: 349-365.

Sastry AN. 1979. Pelecypoda (excluding Ostreidae). En: Giese AC \& JS Pearse (eds). Reproduction of marine invertebrates, Molluscs: Pelecypods and lesser classes 5: 113-292, Academic Press, New York.

Seed R. 1976. Ecology. En: Bayne BL (ed). Marine mussels their ecology and physiology. pp 13-66. Cambridge University Press, Cambridge.

Sokal R \& F Rohlf. 1995. Biometry: The principles and practice of statistics in Biological Research, 887 pp. W. H. Freeman \& Company, New York.

Strub PT, JM Mesías, V Montecinos, J Rutllant \& S Salinas. 1998. Coastal ocean circulation off western South America. En: Robinson AL \& HB Kenneth. The Sea 11: 273-313. John Wiley \& Sons, New York.

Thorarinsdóttir GG \& K Gunnarsson. 2003. Reproductive cycles of Mytilus edulis L. on the west and east coasts of Iceland. Polar Research 22: 217-223.

Toro JE, RJ Thompson \& DJ Innes. 2002. Reproductive isolation and reproductive output in two sympatric mussel species (Mytilus edulis, M. trossulus) and their hybrids from Newfoundland. Marine Biology 141: 897-909.

Urban HJ \& B Campos. 1994. Population dynamics of the bivalves Gari solida, Semele solida and Protothaca thaca from a small bay in Chile at $36^{\circ} \mathrm{S}$. Marine Ecology Progress Series 115: 93-102.

Weibel ER. 1969. Stereological principles for morphometry in electron microscopic cytology. International Review of Cytology 26: 235-302.

Weibel ER \& DM Gomez. 1962. A principle for counting tissue structures on random section. Journal of Applied Physiology 1: 343

Wolff M. 1988. Spawning and recruitment in the Peruvian scallop Argopecten purpuratus. Marine Ecology Progress Series 42: 213-217. 